\title{
DESIGN AND IMPLEMENTATION OF AN ACADEMIC PROJECT FOR FOSTERING OPEN INNOVATION BETWEEN COMPANIES FROM DIFFERENT INDUSTRIAL SECTORS: A CASE STUDY
}

\author{
Juliana GUTIERREZ-ARISTIZABAL and Santiago RUIZ-ARENAS \\ Universidad EAFIT, Colombia
}

\begin{abstract}
Collaborative projects integrating companies and universities have been traditionally conducted between entities from interrelated industrial sectors. Nevertheless, theory about innovation states that the involvement of people from different disciplines, expertise, and type of business foster new perspectives and enables a robust body of knowledge that will derive innovative results. This article aims to share the experience obtained through the planning, and execution of the so-called project "First View Design Lab 2018" (FV). FV is an annual collaborative and academic project organised by Universidad EAFIT that integrates the industry and the academy, in order to find new opportunities of products and services. This project implements design methodologies, co-creation and open innovation to enable knowledge transfer, and to get innovative concepts of new products/services. In 2018, FV was focused on exploring how heterogeneous teams composed by companies from different industrial sectors and the academy contribute to get new concepts that explore other business cores, different from the ones of the companies involved. The process followed enabled overcoming important challenges, such as the reluctance of Colombian companies for working in collaborative projects with other companies and the academy.
\end{abstract}

Keywords: Co-creation, design methodologies, teamwork, design education, collaborative project

\section{INTRODUCTION}

Design methodologies (DM) and practices are used for driving innovation in companies. These methodologies are focused on understanding user needs, and technological challenges for generating new business models, products and services, based on the principles of; observation, collaboration, fast learning, visualisation of ideas, and prototyping [1]. The systematic implementation of these principles through DM, have proven to be effective for deriving ground-breaking innovation, up to the extent that these are used for problem solving and decision-making across the economy [2].

Despite the multiple opportunities that DM represent for companies, these are not widely used in the industrial Colombian context. Moreover, important innovation-related practices such as working in multisector cooperative environments and involving people from different disciplines and expertise are hardly implemented in this context. Local companies are still short-term oriented, and they lack of the formed human capital, resources and networking capabilities [3] for fostering innovation. This situation increases the gap between local and foreign companies, affecting the Colombian industry capability to compete in a globalised world.

Human capital formation for innovation seems to be a suitable way of contributing to the development of Colombian economy [4]. This training process should occur at two main levels: at the company level, with the purpose of familiarising the current company staff with innovation and DM; and, at the undergraduate level, in order to develop the innovation competencies needed in the future company members. This need motivated the development First View Design Lab (FV). FV is an annual collaborative project that integrates multiple companies, and fourth year undergraduate students from the product design engineering programme at Universidad EAFIT, around company's design challenges [5]. Its main objective is to foster knowledge transfer between the involved companies, the academy, and a group of invited experts, as well as contributing to forming new collaboration networks. The main 
characteristic element of this project is that employees from different companies play the role of participants, working hand-in-hand with undergraduate students.

In 2018, FV was mainly focused on integrating companies from different industrial sectors for the development of new business opportunities that could be further implemented in conjunction. For this purpose, two main companies (from now on, company " $\mathrm{A}$ " and company " $\mathrm{B}$ ") were involved. Company "A", is one of the biggest processed food companies in Colombia; and company " $\mathrm{B}$ ", is a private company that provides health, recreation, capacitation, among other welfare services, to the employees' families of a set of affiliated companies.

Besides of the human capital forming, the role of the university in the project was twofold: (i) assure a cooperation environment that encourages diversity, coherence and interactivity [6], and (ii) mediate in the negotiation process between companies, with the purpose of finding a common ground for the project. This last factor represented an important challenge, given the aforementioned characteristics of Colombian companies, which makes them reluctant to collaboration with other industries and with the academy. Moreover, interests from companies and universities may differ significantly, as firms tend to hide results, while universities aim to publish outcomes [7].

This paper is focused on describing the project formulation process followed in order to find a common topic and a set of challenges that would fulfil the interests of the involved companies, as well as the knowledge transfer objectives, and educational interests from the university.

\section{PROCESS DESCRIPTION}

In previous FV projects, one design challenge was formulated for every company. However, the 2018 chapter required finding a common challenge for the participating companies. This challenge definition required conducting two new stages (compared to FV 2016), previous to FV execution: (1) Design challenge formulation, and (2) immersion. Design challenge formulation aimed to identify a common ground between both companies for selecting a topic of interest. Immersion stage's purpose was digging into the identified topic in order to have a deeper understanding of it (see figure 1). The third stage considered in this process corresponded to the execution of the FV project, keeping the main elements proposed in [5]. This article will be mainly focused on stages (1) and (2). Further information about the fundamentals of FV project can be found in [5].

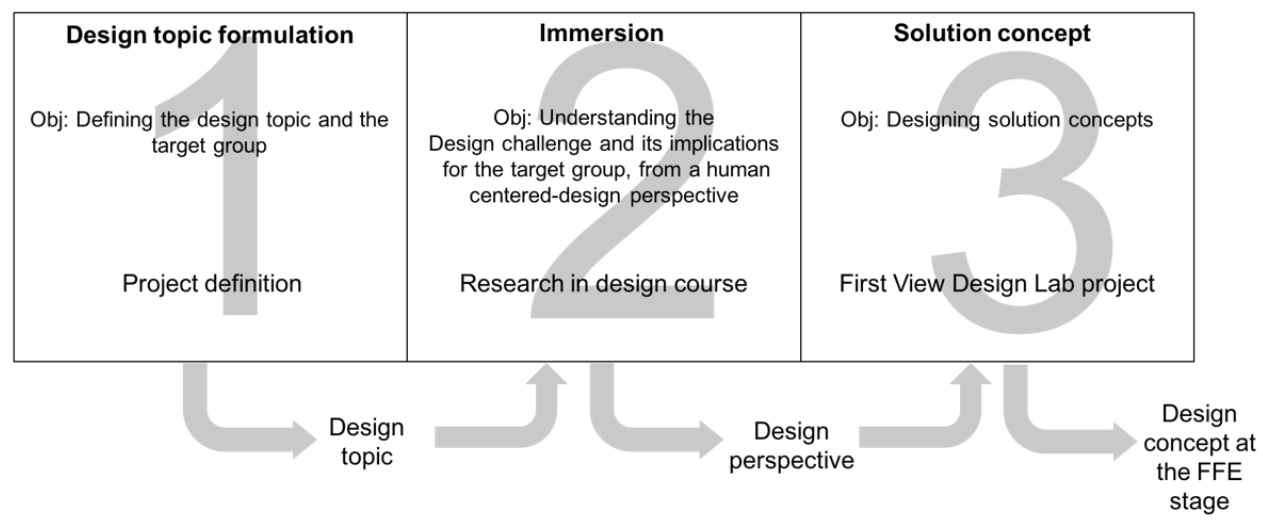

Figure 1. Description of the process

\subsection{Design topic formulation}

The topic formulation was underpinned on the analysis of the Sustainable Development Goals (SDG) defined by the United Nations (UN) in 2015 [8]. These goals aim to provide an agenda for sustainable development in order to achieve a "better and more sustainable future for all", targeted to 2030 [8].

Topic formulation considered the following steps: (i) Identification of the SDGs targeted by each company, (ii) Selection of one common SDG, (iii) target group definition, and (iii) design topic declaration. It is important to highlight that the execution of this stage requires fulfilling two main conditions: (a) both companies should be willing to work in conjunction for deriving concepts that lead to new business models that integrate them; and (b) people at the strategic level of both companies are aligned with the project objectives. A deeper explanation of the above-described steps is presented below: 
i) Identification of the SDGs targeted by every company: this step is conducted by people from R\&D units at companies, under the supervision of the professors involved in the project. Every company analyses its corporate strategy, identifying the SDGs that can be directly impacted by the company. For this purpose, they analyse: (i) mission, vision, and the strategic objectives of the organisation, (ii) business lines, and (iii) product/service portfolio. Once the whole team (company and university members) have a common understanding of the company's strategy, they sort the SDGs, ranging from the ones that can be impacted the most, to the ones that are not impacted at all.

ii) Selection of one common SDG: this is the step whereby members from both companies and the university staff determine a common ground for the project. People involved in the step (i) socialise the results obtained in the identification of the SDGs targeted by their company. A meaningful discussion should be encouraged, enabling, putting over the table the main interests and expectations of both companies. University members chair the discussion. If there is a match between one of the top three SDGs from both companies, the one scored the best in both rankings is chosen. If there is no match, it should be decided, either to continue the project (considering the following SDGs in the rankings) or discarding the initiative.

iii) Target group definition: this step uses as input the market trends analyses conducted by the involved companies. Information coming from business reports, governmental entities, and studies performed by every organisation, feed these analyses. As for the selection of the common SDG, company and academic members should prioritise the potential target groups, selecting the one that fit the best the interests of both companies. The same procedure described in (i) and (ii) is suggested for the accomplishment of this step. The discussion around this subject is critical for finding a common target group. Personas [9] is suggested for documenting and communicating the target group selected.

iv) Design topic declaration: a SDG-related topic should be selected, in order to frame the investigation and design process. This topic should be wide enough to provide multiple opportunity areas, but it should also be restricted to the selected target group. Once the investigation domain is set, the design challenge should be declared. The following structure is proposed: What does the selected topic mean for the selected target group? This question-based declaration triggers a first investigation round that will provide input for concept development.

\subsection{Immersion}

The immersion process was performed in the Design Research course. This is a post-graduation course belonging to the specialisation programme in design management from Universidad EAFIT. This course aims to apply design tools at the Fuzzy Front End, in order to identify design opportunities. The students of the course, who were taught about the User-centred design (HCD) methodology [10], were introduced to the selected topic by their professors, who also explained the assignment.

The immersion process consisted of five main phases, namely: (i) investigation plan, (ii) research execution, (iii) information synthesis and analysis, and (iv) insights and opportunities identification and (v) socialisation and communication.

Throughout this course, post-graduation students get knowledge and practice in the application of design research through a user-centred design approach. The body of knowledge they generate is to be used later to underpin the concept development process. This last stage is performed by undergraduate students and company members participating in FV.

(i) investigation plan: students are divided into smaller groups (up to 5 people). Every single group should define the HCD tools they will use, in order to collect the information required for the research. These tools rank from passive, to active, projective and participatory tools, depending on the knowledge needed. The students should also specify how they will approach the target group, and the places where these sessions will be held. Secondary-sources-based research is encouraged before of the plan definition, in order to familiarise themselves with the target group and the selected topic

(ii) research execution: once the investigation plan is approved by the professor's team and the company members in a socialisation session, the students should execute their plan through field work. The information collected via interviews and observation (among other methods) should be properly documented, to be shared with the other group members and professors. Photos, videos, transcriptions, and drawings, among other evidences, are requested. 
(iii) information synthesis and analysis: All the information collected through the research execution is shared among the group members. Tools for facilitating the information synthesis and analysis, such as clustering [9], are implemented in this step. Once the clusters are formed, these are hierarchised, and their relationships are analysed, enabling a deeper understanding of the object of study. Mindmaps [11] are also used in order to socialise the main findings. Discussion around the obtained clusters and their relationships is encouraged.

(iv) insights and opportunities identification: discussion processes around the synthesised information contributes to reveal insights and opportunities for the companies involved in the project. These findings (insights) constitute a design perspective, needed for guiding the concept development process in further stages.

(v) socialisation and communication: These insights are socialised with company members and professors, for which the course students should design an original way of presenting and explaining results through a product. This product is delivered to the company members in a socialisation meeting, in which students also present their process and their main findings.

\subsection{Solution concept}

The solution concept was developed in the First View Design Lab Project. This project followed the same structure and principles than the previously performed in 2016 [5]. However, two major changes were conducted: (a) the project length was extended (12 weeks length), in order to provide a more suitable time length for the field work, and (b) all the conformed groups had to work in concepts that could be further implemented by both companies in conjunction.

Four groups, comprised of six people, were formed. Each group was composed by four undergraduate students, and two companies' members (one per company), in order to advocate for the company's interests. Every single group was randomly assigned with one of the four design perspectives derived in the stage (2). The purpose behind this assignation was fostering varied solutions that would be underpinned in the different "meanings" identified previously.

FV project was divided into six main phases, namely: (ii) inspiration and exploration, (iii) ideation, (iv) concept development, (v) abstract prototyping, (vi) validation, and (vii) communication and socialisation. The scope of the project was getting four different solution concepts (one per group) that would also consider some basic notions of a business model, including: value proposition, customer segments, revenue streams, key partners, channels, among others. The business model kit [12] was used in order to document the relationship between the involved actors. Every single group delivered an abstract prototype [11] that was socialised with the involved companies.

\section{RESULTS}

At the design topic formulation stage companies followed the above described process. Meaningful discussions took place between the members of both companies and the academic staff. Companies found they had three common SDGs, namely: end of poverty (goal 1), good health and wellbeing (goal 3 ), and responsible production and consumption (goal 12). Despite the SDG selected was good health and wellbeing, the team considered the three of them could be included under the umbrella of wellbeing. The target selected were the Colombian mid class families, as company " $\mathrm{A}$ " had a wide portfolio that covered the whole family members, and company "B" was addressed to provide services for the families. This target is characterised by mostly living in urban areas, having a limited access to bank loans, they are composed by three members (in average), and most of their efforts are addressed to provide quality education for their children. It is important to note, that in the practice, target selection did not follow the proposed process, as it came out spontaneously during the topic definition discussions. The design topic was declared as follows: Contributing to increase the life quality of the Colombian mid class.

At the immersion stage postgraduate students formed four groups. Every single group conducted secondary-source-based. Then, they defined their research plan including, tools such as observation, interviews, dream maps, collage, card sorting, among others. This research derived that wellbeing is associated to four main perspectives: (i) mental and physical balance, (ii) healthy nutrition, (iii) finding their hobbies and passions, and (iv) time management. 
The four perspectives above-mentioned were the main input for FV. They constituted the four strategic directions that were randomly assigned to the new groups. Every single group developed one hundred new ideas at the ideation phase. Three preliminary concepts and one final concept were developed at the implementation phase. Despite all the groups managed to generate concepts that could be commercially implemented by both companies, there were concepts that fitted better in the core of one of the involved organisations. At the request of companies, the derived concepts cannot be presented in this article.

\section{DISCUSSION}

Structuring a consortium of companies that work together around the same project is difficult, due to the different interests, conditions and protocols they have. This process was fully enabled by the university, which mediated between the companies participating in the project. Some of the main critical stages of this process were the negotiation of every party's contributions, and the definition of the common goal. In the former, it was agreed companies would pay in kind, by providing some of the invited experts (international travel expenses), material for DM implementation (paper, markers, Postits ${ }^{\circledR}, \mathrm{t}$-shirts), physical spaces (special meeting rooms), snacks and foods, and transportation. In the last one, the selection of the common SDGs really facilitated this process, by encouraging meaningful discussions that enabled them to stick to their commonalities, rather than their differences.

The decision about the company's contributions (working as partners rather than clients) was made, in order to attract company interest (considering they are reluctant to invest in this kind of projects). The main argue behind this decision was that companies can witness the value that working with universities can provide, while students can experience real-industry challenges. It was a long-term goal, as it is expected the companies start to invest in further projects with the university, including academic and research projects of large scale. At the "Research in Design" course, the participation of important company members enriched the class sessions, which was valuable for the involved postgraduate students. Likewise, the results obtained in this course increased the interest of companies for participating in FV.

The role of the university in the FV execution was fundamental for keeping the focus of the project and for integrating the different parties. The professors involved ensured the fulfilling of the interests of both companies, as well as the knowledge goals. Participating company members were provided with new tools for problem solving and were familiarised with DM and innovation principles. Undergraduate students were taught about DM and had the chance to interact with people working at companies, making presentations to company directors, and experiencing the reality of the industrial context.

The nature of the project (Fuzzy Front End stage), and the low amount of money invested, allowed the companies to explore different opportunities. The invited company members (directors of the different areas of the company) expressed their satisfaction with the derived concepts, up to the extent that FV students were invited to the headquarters of both companies to socialise their concepts. Results obtained suggest that this type of projects contribute to overcome the bias resulting from the daily practice of activities concerning their businesses, providing new business opportunities for both companies that had hardly obtained without their participation in this project.

\section{CONCLUSIONS}

This article presents the process followed for the formulation and execution of the so-called project: First View Design Lab 2018. This project aimed to transfer knowledge about the application of Design Methodologies for fostering innovation at Colombian companies. Its main characteristic is the integration of undergraduate students, and company members working hand-in-hand in the development of new products and services. The main challenge faced is the reluctance of Colombian companies to collaborate with other companies and with the academy, and the need of getting solutions that can be commercially implemented by both companies in conjunction. The process followed implied using the SDGs as a mean for finding a common ground between the companies involved, and the use of interconnected projects for attracting company's interest. At the end of the project, company members were familiarised with DM and innovation processes, companies witnessed the benefits of working with universities, and the involved students experienced the reality of the industrial context. It was evidenced that the systematisation of the process enabled the companies to visualise common opportunities that would have been difficult to envision in a different context. In this matter, the university played an important role in this collaborative project. The neutral role that the university played in this project contributed to the mediation, in order to satisfy the needs and expectations of the different stakeholders. 
Additionally, it contributed to align the entities and maintain the focus on a common result that would benefit all the parties. The execution of the FV 2018 version, evidenced that mechanisms for the implementation of new common business models are needed in order to enable companies to further develop these concepts in conjunction. For future research, it is proposed to analyse legal, economic and human resource strategies, that will propitiate the commercial implementation of some of the resulting initiatives. The research should also focus on analysing the role of the university and how it can contribute in this process.

\section{REFERENCES}

[1] Lockwood T. Design thinking: Integrating innovation, customer experience, and brand value, 3rd edition, 2009 (New York: Allworth Press).

[2] Design Council. Designing a Future Economy. Available: https://www.designcouncil.org.uk/resources/report/designing-future-economy-report [Accessed on 2019, 11, 03] (2018)

[3] Zanello G., Fu X., Mohnen P. and Ventresca M. The creation and diffusion of innovation in developing countries: a systematic literature review. Journal of Economic Surveys, 2016 30(5), 884-912.

[4] Jimenes Ibañez J.E. Análisis y desarrollo de un modelo de tutorización integral basado en el Design Thinking orientado a la innovación estratégica en empresas colombianas, (2017) (Universitat Politecnica de Valencia). Doctoral dissertation

[5] Hernandez-Monsalve M.E., Velasquez-Montoya M., Mejia-Gutierrez R., Hohn H. and Tassoul M. First View DesignLab: A fuzzy front-end platform for innovation and education, In Proceedings of the 21st International Conference on Engineering Design, ICED'17, Vol. 9, Vancouver, August 2, 99.189-198

[6] Alves J., Marques M.J., Saur I. and Marques, P. Creativity and Innovation through Multidisciplinary and Multisectoral Cooperation. Creativity and Innovation Management, 2007, $16,27-34$.

[7] Gomez F.A., Daim T.U. and Robledo J. Characterisation of the Relationship Between Firms and Universities and Innovation Performance: The Case of Colombian Firms. Journal of Technology Management \& Innovation, 2014, 9(1).

[8] United Nations. About the Sustainable Development Goals. Available: https://www.un.org/sustainabledevelopment/sustainable-development-goals/ [Accessed on 2019, $11,03]$.

[9] Kumar V. 101 Design Methods: A Structured Approach for Driving Innovation in Your Organisation. 2013 (John Wiley \& Sons, Inc).

[10] IDEO. The Field Guide to Human-centred Design, 2015 (IDEO.org)

[11] Van der Schoor R., Van Boeijen A., Daalhuizen J. and Zijlstra J. Delft Design Guide: Design strategies and methods, 2013 (Bis Publishers Bv)

[12] Board of innovation. Business Model Kit. Available: https://www.boardofinnovation.com/tools/business-model-kit/ [Accessed on 2019, 11, 03]. 